УДК 338.43. 68.75.01

\title{
СОВЕРШЕНСТВОВАНИЕ МЕТОДИКИ РАСЧЁТА РЕГИОНАЛЬНОГО ВАЛОВОГО ПРОДУКТА АПК РЯЗАНСКОЙ ОБЛАСТИ
}

\author{
(C) 2012 г. A. Н. Гусев
}

\section{Рязанский государственный агротехнический университет им. П. А. Костычева}

В современной методике расчёта регионального валового продукта сельского хозяйства имеются методологические погрешности, в частности, присутствует повторный счёт. Это приводит к искажению расчётных показателей объёмов производства, показателей эффективности. Указанная проблема наиболее актуальна для сельскохозяйственных организаций, производящих молочную продукцию. Предлагаемый порядок расчёта объёма валовой продукции осуществляется по конечным результатам использования кормов, то есть через продукиию животноводства.

Ключевые слова: молочное животноводство; корректировка; корма; валовая продукичи сельского хозяйства; валовой региональный продукт.

In the nowadays widely used method of calculating the regional gross product volume for the region's agriculture exist a number of methodological mistakes, in particular, there is double counting. This leads to a distortion of the calculated levels of production, as of the performance indicators. This problem is the most acute for agricultural enterprises, producing dairy products. The proposed procedure for calculating the volume of total production is carried out on the final results of the feed use, that is, on the volumes of the livestock products.

Key words: dairy cattle; the adjustment; food; gross agricultural output; gross regional product.

Одним из важных показателей, характеризующих экономическую эффективность аграрного производства, является показатель объёма валовой продукции, который исчисляется как по отдельным сельскохозяйственным организациям, так и по региону в целом. В настоящее время в формах статистической отчётности, отражающих деятельность сельскохозяйственных организаций в разделе «Основные показатели сельского хозяйства», продукция, исчисляемая в фактических ценах, представлена как продукция растениеводства и животноводства. Суммирование вышеуказанных показателей представляет собой валовую продукцию сельского хозяйства, полученную за определённый промежуток времени [3]. Базой данных для расчета являются статистические показатели деятельности сельскохозяйственных организаций региона. Под валовой продукцией сельского хозяйства понимается суммарное ее количество, произведенное за какой-то промежуток времени, как правило, за год.

Объём производства валового регионального продукта сельскохозяйственной отрасли Рязанской области в текущих ценах по годам представлен в таблице 1.

Согласно расчётам, в области наблюдается тенденция сокращения объёмов производства валовой продукции с 2008 г. по 2010 г. на $11,5 \%$, в том числе по отрасли растениеводства на $11,7 \%$, по отрасли животноводства на $11,2 \%$. Главная причина таких изменений кроется в сокращении объемов производства в натуральном выражении. Даже неуклонный рост реализационных цен на продукцию не смог оказать стабилизирующего влияния.

В расчётах объёмов производства валовой продукции сельского хозяйства имеются методологические погрешности, а именно, 
Таблица 1

\section{Продукция сельского хозяйства Рязанской области в фактических ценах} за период 2008-2010 гг., млн. руб.

\begin{tabular}{|c|c|c|c|}
\hline \multirow{2}{*}{ Годы } & Продукция сельского & \multicolumn{2}{|c|}{ В том числе } \\
\cline { 3 - 4 } & хозяйства всего & растениеводство & животноводство \\
\hline 2008 & 28420,8 & 16520,0 & 11900,8 \\
\hline 2009 & 23308,4 & 12045,0 & 11263,4 \\
\hline 2010 & 25146,0 & 14581,3 & 10564,7 \\
\hline
\end{tabular}

присутствует повторный счёт. Особо актуальна эта проблема при оценке эффективности работы отрасли молочного животноводства, так как эта отрасль тесно связана с растениеводческой отраслью, которая обеспечивает кормами животных. В современных условиях многие сельскохозяйственные организации, имеющие молочную специализацию, как правило, развивают свою собственную кормовую базу. Таким образом, при оценке эффективности продукция отрасли кормопроизводства учитывается дважды - вначале в общем объёме валовой продукции растениеводства, а затем через валовую продукцию животноводства, полученную в результате использования кормов. Данная ситуация приводит к тому, что, чем выше уровень развития кормовой базы, тем выше вероятность искажения показателей эффективности работы отрасли животноводства.

Рост объёмов валовой продукции, как считают некоторые специалисты [1], создаёт иллюзию благоприятного состояния дел в отрасли, но реально не означает увеличения производства и потребления и не позволяет объективно судить об уровне развития сельскохозяйственного производства.

По нашему мнению, решение данной проблемы возможно по следующей формуле:

$$
\left.V_{b n}=\sum_{i=1}^{\mathrm{n}}\left[\left(V+P_{\phi}\right) \cdot\left(L_{\varkappa} / C_{\sigma}\right) \cdot K\right) \cdot L_{\varkappa}\right]
$$

где $V_{s p}$ - объем валовой продукции сельского хозяйства, руб.; $V$ - объем растениеводческой продукции имеющий кормовое назначение, ц к. ед.; $P_{\phi}-$ фактический расход кормов на единицу животноводческой продукции ц к. ед.; $Ц_{\varkappa}$ - средняя цена реализации единицы животноводческой продукции, руб.; $C_{\sigma}-$ себе- стоимость 1 ц животноводческой продукции, руб.; $K-$ коэффициент удельного веса затрат кормов в структуре себестоимости животноводческой продукции.

Специализация сельскохозяйственных предприятий преимущественно на одном виде животноводческой продукции позволяет рассчитать объем полученной валовой продукции, по формуле 1 при $i=1$. При расчете этого объема через продукцию животноводства в хозяйствах, специализирующихся на нескольких их видах, общий объем кормов, при отсутствии достоверного учета их использования по отраслям, следует распределять на виды продукции, исходя из структуры товарной продукции животноводства.

Данная методика расчета была апробирована на региональном уровне при оценке эффективности работы отрасли сельского хозяйства Рязанской области (табл. 2).

Таким образом, за анализируемый период наблюдается негативная тенденция сокращения объёмов кормовой продукции для отрасли молочного скотоводства. За сравнительно короткий период сократилось производства кормов на 1223759,2 ц к. ед., или на $24 \%$. Причём сокращение объёмов происходит по всей номенклатуре кормовой продукции.

Все представленные в таблице корма содержат микро- и макроэлементы в различном количестве.

Денежная оценка объемов производства кормов осуществлялась исходя из расчёта эталона 1 ц овса, который приравнивается к 1 ц кормовых единиц и удельного веса в других видах кормов кормовых единиц, а также с учётом средней цены реализации овса на рынке. Так, к примеру, в 2008 г. этот показатель был на уровне 402,3 руб./ц, в 2009 г. - 283 руб./ц, в 2010 г. - 306,6 руб./ц. 


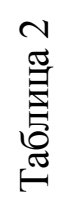

\begin{tabular}{|c|c|c|c|c|c|c|c|c|c|c|c|c|}
\hline \multicolumn{2}{|l|}{ 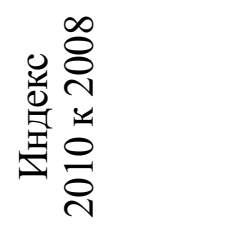 } & $\frac{N}{0}$ & $\vec{\sigma}$ & $\frac{\infty}{0}$ & $\underset{0}{\forall}$ & 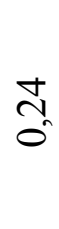 & $\tilde{n}_{0}$ & $\frac{n}{0}$ & $\mathbb{J}_{0}$ & $\begin{array}{l}\stackrel{n}{m}= \\
0 \\
0\end{array}$ & $\bar{\sigma}_{0}$ & $\frac{0}{0}$ \\
\hline \multirow{2}{*}{$\stackrel{\circ}{\stackrel{0}{0}}$} & 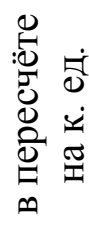 & $\frac{2}{6}$ & $\begin{array}{l}0 \\
\infty \\
\infty \\
\hat{0} \\
n \\
n \\
n\end{array}$ & 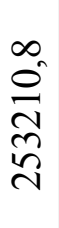 & $\begin{array}{l}0 \\
\infty \\
\infty \\
N\end{array}$ & 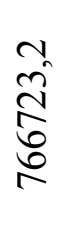 & $\begin{array}{l}\hat{\sigma} \\
\stackrel{2}{n} \\
\frac{n}{n}\end{array}$ & $\begin{array}{l}n \\
\tilde{n} \\
\tilde{n} \\
\tilde{\sigma}\end{array}$ & $\frac{n}{n}$ & 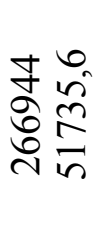 & $\frac{\infty}{\sigma}$ & 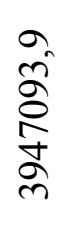 \\
\hline & 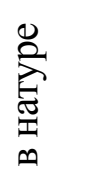 & $\begin{array}{l}2 \\
\text { } \\
\text { }\end{array}$ & $\underset{\frac{7}{8}}{\stackrel{ }{8}}$ & \begin{tabular}{l}
$\hat{N}$ \\
$\hat{\sigma}$ \\
\multirow{2}{*}{}
\end{tabular} & $\begin{array}{l}\curvearrowleft \\
\infty \\
\infty \\
n\end{array}$ & $\begin{array}{l}\infty \\
0 \\
0 \\
0 \\
0 \\
0\end{array}$ & $\begin{array}{l}\hat{\infty} \\
0 \\
0 \\
\mathscr{0} \\
0\end{array}$ & $\begin{array}{l}\text { సે } \\
\text { ळે } \\
\text { ळે }\end{array}$ & $\begin{array}{l}\text { 으 } \\
\text { ஸे } \\
\stackrel{0}{N}\end{array}$ & 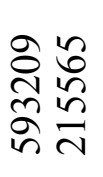 & 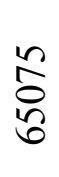 & $x$ \\
\hline 8 & 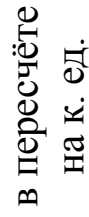 & $\stackrel{\text { g }}{=}$ & 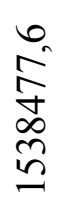 & 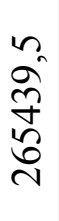 & 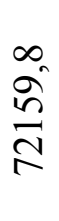 & $\begin{array}{l}8 \\
\stackrel{\infty}{8} \\
\infty \\
=\end{array}$ & $\begin{array}{l}\infty \\
\infty \\
0 \\
0 \\
\infty \\
\infty \\
m\end{array}$ & $\frac{\Delta}{\frac{D}{n}}$ & 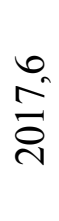 & 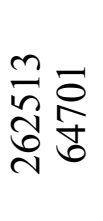 & $\begin{array}{l}\infty \\
\stackrel{\infty}{\infty} \\
\stackrel{+}{+}\end{array}$ & $\begin{array}{l}n \\
0 \\
n \\
n \\
n \\
\frac{n}{\gamma}\end{array}$ \\
\hline
\end{tabular}

畧 강

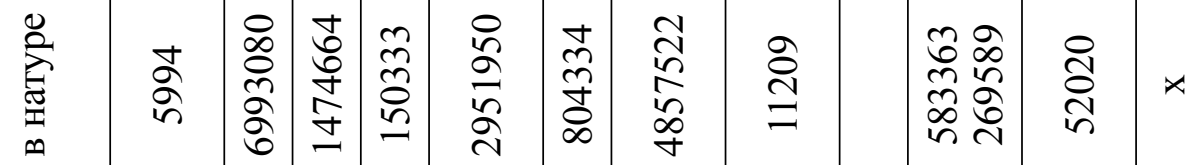

\begin{tabular}{|c|c|c|c|c|c|c|c|c|c|c|c|c|c|c|}
\hline & & $\infty$ & & bे & $\Xi$ & - & $\grave{\imath}$ & $\infty$ & $\underset{+}{\infty}$ & & & $n \sim$ & & \\
\hline & $\stackrel{\infty}{8}$ & 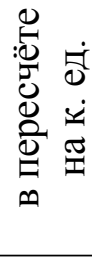 & 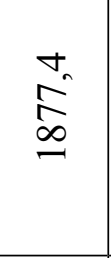 & 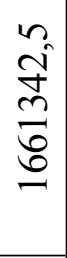 & $\begin{array}{l}\text { ते } \\
\text { तે }\end{array}$ & $\begin{array}{l}a \\
\hat{0} \\
\frac{a}{2}\end{array}$ & 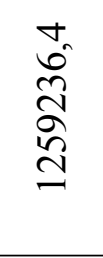 & $\begin{array}{l}\infty \\
\infty \\
\infty \\
\infty \\
\infty \\
y\end{array}$ & 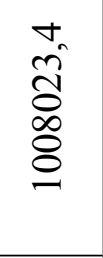 & $\begin{array}{l}\infty \\
\stackrel{\infty}{\infty} \\
\stackrel{\infty}{0}\end{array}$ & & 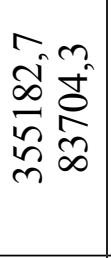 & $\frac{\Omega}{\frac{\Omega}{2}}$ & $\begin{array}{l}\vec{n} \\
\hat{n} \\
\infty \\
0 \\
\bar{n} \\
n\end{array}$ \\
\hline & & 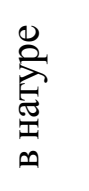 & $\begin{array}{l}\hat{\infty} \\
\text { ñ }\end{array}$ & $\begin{array}{l}n \\
\frac{n}{n} \\
n \\
n\end{array}$ & $\begin{array}{l}8 \\
8 \\
\frac{1}{8} \\
\text { + }\end{array}$ & $\frac{1}{2}$ & $\begin{array}{l}\overline{8} \\
\dot{\infty} \\
\dot{\infty}\end{array}$ & \begin{tabular}{l}
8 \\
$\stackrel{8}{n}$ \\
\multirow{2}{2}{}
\end{tabular} & 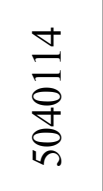 & $\begin{array}{l}\stackrel{8}{0} \\
\stackrel{n}{=}\end{array}$ & & 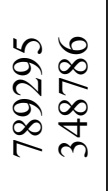 & $\begin{array}{l}\infty \\
\stackrel{+}{+} \\
\infty \\
\text { m }\end{array}$ & $x$ \\
\hline 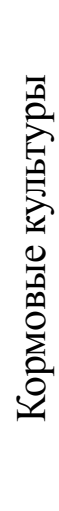 & & & 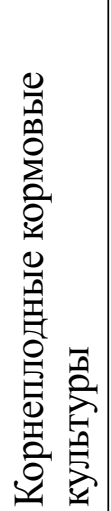 & 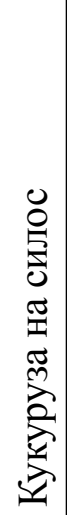 & 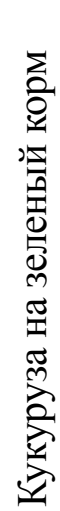 & 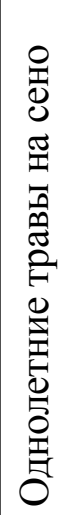 & 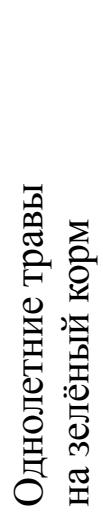 & 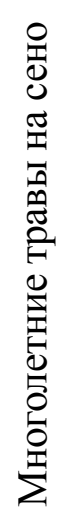 & 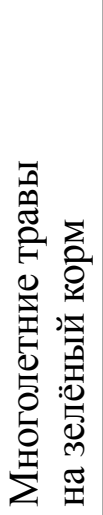 & 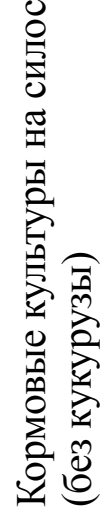 & 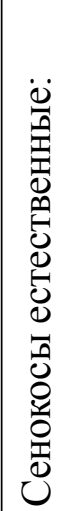 & 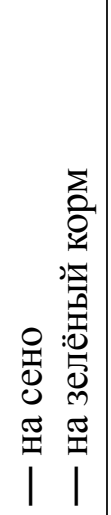 & 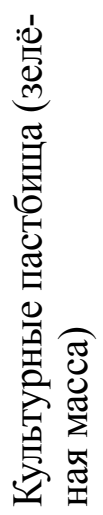 & 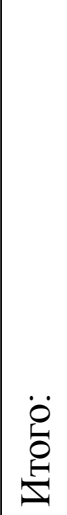 \\
\hline
\end{tabular}


Таким образом, если в 1 ц сена многолетних трав содержится 0,48 ц к. ед., то стоимость 1 ц сена будет в 2010 г. составлять 147,17 руб. (306,6 руб./ц • 0,48). Такой пересчёт производится по всем видам кормов (табл. 3).

В результате пересчёта фактических объёмов производства кормов с учётом содержания в них кормовых единиц на среднюю реализационную цену овса, выявляются размеры погрешности повторного счёта продукции кормопроизводства в общем объёме валовой продукции сельского хозяйства.

Данный расчёт позволяет выявить реальные размеры недостатков повторного счёта в денежном эквиваленте. Так, согласно нашим расчётам, объём валовой продукции сельского хозяйства, производимый сельскохозяйственными организациями Рязанской области, был существенно завышен в 2008 г. на 615027,2 тыс. руб., в 2009 г. — на 343839,6 тыс. руб., в 2010 г. - на 356689,0 тыс. руб.

В табл. 4 проведен пересчет валового производства молока в регионе через объёмы производства кормов по алгоритму приведенной формулы.

В результате расчёта показателя объёма валовой продукции сельского хозяйства

Таблица 3

\section{Результаты корректировки и денежной оценки объёмов производства кормов с учётом их качественных характеристик, ориентированных на среднюю реализационную цену овса, сложившуюся в регионе, тыс. руб.}

\begin{tabular}{|c|c|c|c|}
\hline \multirow[t]{2}{*}{ Кормовые культуры } & \multicolumn{3}{|c|}{ годы } \\
\hline & 2008 & 2009 & 2010 \\
\hline $\begin{array}{l}\text { Корнеплодные } \\
\text { кормовые культуры }\end{array}$ & 151,0 & 67,9 & 415,9 \\
\hline Кукуруза на силос & 147859,4 & 95385,6 & 104277,7 \\
\hline $\begin{array}{l}\text { Кукуруза на зеленый } \\
\text { корм }\end{array}$ & 1861,7 & 13545,4 & 19726,2 \\
\hline $\begin{array}{l}\text { Однолетние травы на } \\
\text { сено }\end{array}$ & 15402,6 & 9819,5 & 10863,4 \\
\hline $\begin{array}{l}\text { Однолетние травы на } \\
\text { зелёный корм }\end{array}$ & 202737,1 & 133428,1 & 94030,9 \\
\hline $\begin{array}{l}\text { Многолетние травы } \\
\text { на сено }\end{array}$ & 88430,4 & 52537,8 & 46335,8 \\
\hline $\begin{array}{l}\text { Многолетние травы } \\
\text { на зелёный корм }\end{array}$ & 85177,9 & 204,0 & 38971,6 \\
\hline $\begin{array}{l}\text { Кормовые культуры } \\
\text { на силос } \\
\text { (без кукурузы) }\end{array}$ & 150,6 & 102,9 & 281,5 \\
\hline \multicolumn{4}{|l|}{$\begin{array}{l}\text { Сенокосы } \\
\text { естественные: }\end{array}$} \\
\hline $\begin{array}{l}\text { — на сено } \\
\text { — на зелёный корм }\end{array}$ & $\begin{array}{c}64281,1 \\
8081,6\end{array}$ & $\begin{array}{c}33496,6 \\
4402,3\end{array}$ & $\begin{array}{c}36830,2 \\
3806,7\end{array}$ \\
\hline $\begin{array}{l}\text { Культурные пастби- } \\
\text { ща (зелёная масса) }\end{array}$ & 889,9 & 849,5 & 1149,1 \\
\hline Итого: & 615027,2 & 343839,6 & 356689,0 \\
\hline
\end{tabular}


Таблица 4

\section{Пересчёт валового производства молока в регионе через объёмы производства кормов}

\begin{tabular}{|c|c|c|c|c|c|c|}
\hline \multirow[t]{2}{*}{ Годы } & \multicolumn{6}{|c|}{ Показатели } \\
\hline & $V$, ц к.ед. & $\begin{array}{c}P_{\phi}, \\
\text { ц к. ед. }\end{array}$ & $\begin{array}{c}\boldsymbol{U}_{\dddot{x},} \\
\text { pyб̄./ц }\end{array}$ & $\begin{array}{c}C_{\tilde{\sigma}}, \\
\text { руб./ц }\end{array}$ & K & $\begin{array}{c}\text { Валовое } \\
\text { производство } \\
\text { молока, млн. руб. }\end{array}$ \\
\hline 2008 & 5170853,1 & 1,2 & 931,4 & 805,0 & 0,74 & 3435,2 \\
\hline 2009 & 4757356,6 & 1,21 & 877,7 & 835,0 & 0,74 & 2737,6 \\
\hline 2010 & 3947093,9 & 1,21 & 1021,0 & 916,0 & 0,74 & 2732,9 \\
\hline
\end{tabular}

(молока) за период 2008-2010 гг. через продукцию кормопроизводства было выявлено, что этот показатель был необоснованно завышен в 2008 г. на 3435,2 млн. руб., в 2009 г. — на 2737,6 млн. руб., в 2010 г. — на 2732,9 млн. руб. Сокращение размеров валовой продукции на указанные суммы, на наш взгляд, дали бы более объективную оценку деятельности отрасли, значительно сократив валовую продукцию растениеводства, так как часть её была продуктивно использована и имела кормовое назначение для отрасли животноводства при производстве молока.

В результате корректировки, показатели объёмов валовой продукции сельского хозяйства региона, как в целом, так и в отраслевом разрезе, представлены в табл. 5.

Представленные данные свидетельствуют о снижении объёма валовой продукции в результате корректировки в сравнении с данными табл. 1.

Проблема объективного исчисления объёма валового регионального продукта весь- ма актуальна, так как он является системообразующим показателем, участвующим в расчётах таких показателей как производительность труда (годовая, дневная, часовая), показателей, отражающих результативность интенсификации аграрного производства и других. В масштабах государства размеры такой корректировки могут представлять внушительные цифры. Таким образом, такая методика расчёта валового регионального продукта отрасли сельского хозяйства, в определённой мере, позволяет устранить недостатки повторного счёта.

\section{Литература}

1. Зельднер $A$. Г. Валовая продукция сельского хозяйства: иллюзия роста и реальная действительность. // Экономика сельскохозяйственных и перерабатывающих предприятий. - 2010. — №2 - C. 12-14.

2. Рязанская область в цифрах, 2011: стат. сб. - Рязань: Рязаньстат, 2011. — 283 с.

Таблица 5

Объём валовой продукции сельского хозяйства Рязанской области в результате корректировки, млн. руб.

\begin{tabular}{|c|c|c|c|}
\hline \multirow[t]{2}{*}{ Годы } & \multirow{2}{*}{$\begin{array}{c}\text { продукция сельского } \\
\text { хозяйства, всего }\end{array}$} & \multicolumn{2}{|c|}{ в том числе } \\
\hline & & растениеводство & животноводство \\
\hline 2008 & 24985,6 & 13084,8 & 11900,8 \\
\hline 2009 & 20570,8 & 9307,4 & 11263,4 \\
\hline 2010 & 22413,1 & 11848,4 & 10564,7 \\
\hline
\end{tabular}


3. Сельское хозяйство Рязанской области: стат. сб. - Рязань: Рязаньстат, 2010. $152 \mathrm{c}$.

4. Состояние животноводства в сель- скохозяйственных организациях Рязанской области в 2011 г. - Рязань: Рязаньстат, 2012. $-108 \mathrm{c}$.

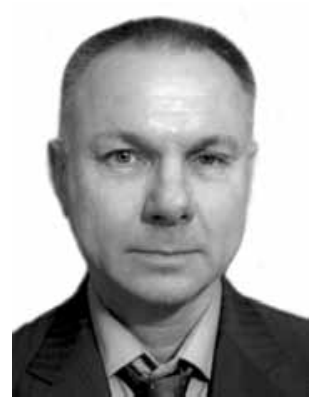

Андрей Юрьевич Гусев - кандидат экономических наук, доцент Рязанского государственного агротехнического университета им. профессора П. А. Костычева.

Andrey Yurievich Gusev - Ph.D. Candidate of Economics, docent at the Ryasan State Agrotechnical University of the professor P. A. Kostychev name.

390044, г. Рязань, ул. Костычева, д. 1

1 Kostycheva st., 390044, Ryazan, Russia

Тел.: +7 (4912) 35-88-31; e-mail: a.y.gusev@mail.ru

\title{
МИНИСТЕРСТВО ОБРАЗОВАНИЯ И НАУКИ РФ \\ ПРАВИТЕЛЬСТВО ПЕНЗЕНСКОЙ ОБЛАСТИ \\ АКАДЕМИЯ ПРОБЛЕМ КАЧЕСТВА РФ \\ АКАДЕМИЯ ИНФОРМАТИЗАЦИИ ОБРАЗОВАНИЯ \\ РОССИЙСКАЯ АКАДЕМИЯ КОСМОНАВТИКИ \\ ПЕНЗЕНСКИЙ ГОСУДАРСТВЕННЫЙ УНИВЕРСИТЕТ
}

\author{
с 27 мая по Зиюня 2013 года \\ проводят в г. Пензе \\ межсународный симпозиум \\ «НАДЁЖНОСТЬ И КАЧЕСТВО», \\ посвящённый 350-летию г. Пензы
}

Официальные языки симпозиума - русский и английский

Оперативная связь с Оргкомитетом: тел./факс: +7 (841-2) 56-43-46 тел.: +7 (841-2) 36-82-12

http://www.nika-penza.ru, www.arikos.ru

E-mail: kipra@pnzgu.ru,nika@nika-penza.ru 